\title{
Supramolecular Template-Directed In Situ Click Chemistry: A Bioinspired Approach to Synthesize G- Quadruplex DNA Ligands
}

Tanima Bhattacharyya, Deepanjan Panda and Jyotirmayee Dash*

School of Chemical Sciences, Indian Association for the Cultivation of Science, Jadavpur, Kolkata-700032, India; Email:ocjd@iacs.res.in 


\section{Supporting Information}

\section{Table of Contents}

$1.0 \quad$ General Experimental $\quad$ S3

2.0 Preparation of the G4-PhB hydrogel $\quad$ S4

3.0 Characterization of the hydrogel S4

3.1 Powder X-ray Diffraction (PXRD) study $\quad$ S4

3.2 CD analysis of the hydrogel $\quad$ S5

3.3 AFM and TEM analysis $\quad$ S6

3.4 NMR Spectroscopy (Solution phase) S6

3.5 Rheological measurements $\quad$ S6

$\begin{array}{lll}3.6 & \text { DSC analysis of the hydrogel } & \text { S7 }\end{array}$

$\begin{array}{lll}\text { 4.0 Preparation and characterization of compounds } & \text { S7 }\end{array}$

$\begin{array}{lll}4.1 & \text { Synthesis of triazole product } 7 & \text { S7 }\end{array}$

4.2 $\quad{ }^{1} \mathrm{H}$ NMR and ${ }^{13} \mathrm{C}$ NMR spectra of compound $7 \quad$ S9

$\begin{array}{lll}5.0 & \text { HPLC chromatograms of compound } \mathbf{6} \text { and } \mathbf{7} & \text { S10 }\end{array}$

$\begin{array}{lll}6.0 & \mathrm{G} 4-\mathrm{PhB} \text { templated cycloaddition } & \mathrm{S} 10\end{array}$

6.1 Control Experiments $\quad$ S11

6.2 Determination of the rate of reaction $\quad$ S11

6.3 Determination of the regiochemistry of the compound $6 \quad$ S15

$\begin{array}{lll}7.0 & \text { G-BrG templated cycloaddition } & \text { S16 }\end{array}$

$\begin{array}{llr}8.0 & \text { References } & \text { S17 }\end{array}$ 


\subsection{General Experimental:}

All reagents were purchased from Sigma Aldrich or TCI and used as received unless otherwise stated. NMR solvent $\left(\mathrm{D}_{2} \mathrm{O}\right)$ and $\left(\mathrm{DMSO}-\mathrm{d}_{6}\right)$ were purchased from Sigma Aldrich and used as received.

Powder X- ray Diffraction (PXRD) experiment was carried out with a dried thin film of the gel on a glass slide using an X'Pert PRO X-ray Powder Diffractometer (PANalytical, Netherlands made) from an angle range of $20^{\circ}$ to $35^{\circ}$. Circular Dichroism (CD) spectrum was recorded with the hydrogel at room temperature using a $1 \mathrm{~mm}$ path length quartz cuvette using a JASCO J-815 spectrophotometer. The CD spectrum, represents an average of three scans and was smoothed and zero corrected. Transmission Electron Microscope (TEM) images were recorded using a JEM 2011 JEOL electron microscope, operated at an acceleration voltage of $120 \mathrm{keV}$. The sample was prepared by drop casting the aqueous dispersion of the G4-PhB hydrogel onto a carbon-coated 300 mesh copper grid, followed by drying under room temperature. Atomic Force Microscope (AFM) images were recorded using a tapping mode Veeco diCP-II AFM. Aqueous solution of the G4-PhB hydrogel was dropped onto freshly cleaved mica surface and dried in air at room temperature overnight to prepare the sample for AFM. Rheological measurements were performed using $2 \mathrm{~mL}$ of gel samples in an Anton Paar Modular Compact rheometer (Model: MCR 102) at $25{ }^{\circ} \mathrm{C}$. Differential Scanning Calorimetry (DSC) was carried out with required amount of the hydrogels in the range of $-10{ }^{\circ} \mathrm{C}$ to $80{ }^{\circ} \mathrm{Cusing} \mathrm{LVC}$ pans in a Perkin Elmer made Diamond DSC machine at a scan rate of $2{ }^{\circ} \mathrm{C} \mathrm{min}^{-1}$.

All compounds synthesized were characterized by ${ }^{1} \mathrm{H} \mathrm{NMR},{ }^{13} \mathrm{C} \mathrm{NMR}$ and HRMS. ${ }^{1} \mathrm{H}$ NMR and ${ }^{13} \mathrm{C}$ NMR were recorded on Bruker $400 \mathrm{MHz}$ NMR spectrometer. Chemical shifts have been expressed in ppm values. The ${ }^{1} \mathrm{H}$ NMR chemical shifts were internally referenced using residual protonated solvent signal as internal standard $\left(\delta 4.79\right.$ for $\mathrm{D}_{2} \mathrm{O}, \delta$ 2.54 for DMSO-d 6 ). ${ }^{13} \mathrm{C}$ NMR chemical shifts were internally referenced to the solvent resonance ( $\delta 40.45$ for DMSO- $\mathrm{d}_{6}$ ). Peak multiplicities are designated by the following abbreviations: s, singlet; br.s, broad singlet; d, doublet; t, triplet; q, quartet; m, multiplet; $J$, coupling constant in Hz. The coupling constant $J(\mathrm{~Hz})$ has been rounded to one decimal place for all compounds. Where a coupling pattern can be assigned as a combination of multiplicities, the above abbreviations have been combined to describe the observed patterns (i.e., dt - doublet of triplets). HRMS analyses were performed with Q-TOF 
YA263 high resolution (Water Corporation, Australia) instruments by +ve mode electrospray ionization.

The microwave irradiation experiment was conducted in Biotage Microwave synthesis system (Initiator EXP. EU, Biotage Sweden AB) operating at a frequency of $2.45 \mathrm{GHz}$, power $300 \mathrm{~W}$ ). The reaction was carried out in a sealed microwave vial and temperature was set to a constant temperature of $70{ }^{\circ} \mathrm{C}$ for the whole reaction time of 4 hours. After the reaction time was over and the microwave irradiation stopped, the reaction vial was allowed to remain in the reactor and cool till the reactor lid opened by itself.

HPLC analyses were performed using SHIMADZU, SPD-20A system equipped with a Waters Spherisorb ${ }^{\circledR} 5.0 \mu \mathrm{m}$ ODS2 column 4.6 x $250 \mathrm{~mm}$ using $254 \mathrm{~nm}$ detection

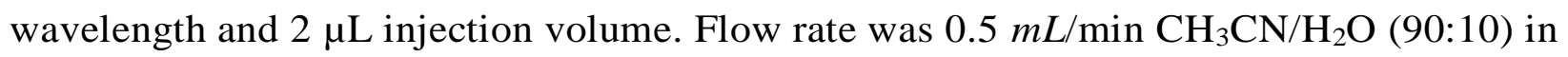
$0.1 \%$ TFA over 20 minutes.

\subsection{Preparation of the G4-PhB hydrogel:}

The guanosine-phenylboronic acid hydrogel was synthesized using nucleoside guanosine $\mathbf{1}$ and phenylboronic acid $\mathbf{2}$ in the presence of $\mathrm{KOH}$. A mixture of guanosine, $\mathbf{1}$ (10 mg, 0.035 mmol), phenylboronic acid 2, (4.3 mg, $0.035 \mathrm{mmol}, 1.0$ equiv.) and $\mathrm{KOH}(1.4 \mathrm{mg}, 0.025 \mathrm{mmol}$, 0.7 equiv.) in $0.5 \mathrm{~mL}$ MilliQ water was heated at $100{ }^{\circ} \mathrm{C}$ until a clear solution was obtained. The resulting solution was allowed to cool to ambient temperature and left undisturbed to form the gel. A clear and strong gel was formed within $5 \mathrm{~min}$. The $\mathrm{pH}$ of these gels were found to be $\sim 8$. The gel once formed was stable for a $\mathrm{pH}$ range of 12-7. Beyond this $\mathrm{pH}$ range the gel decomposed resulting in white precipitation and became a clear sol at $\mathrm{pH}<2$.

\subsection{Characterization of the guanosine-boronic acid hydrogel (G4-PhB hydrogel):}

3.1 Powder X- ray Diffraction (PXRD) study: The PXRD pattern (Figure S1) obtained, showed a broad peak at $26.7^{\circ}(d=0.33 \mathrm{~nm})$, which is characteristic of the stacking interaction of 
G-quartets in DNA G-quadruplexes. This study indicated that the arrangement of the G-quartets in the gel fibers is similar to the arrangement of the G-quartets in DNA G-quadruplexes. ${ }^{1}$

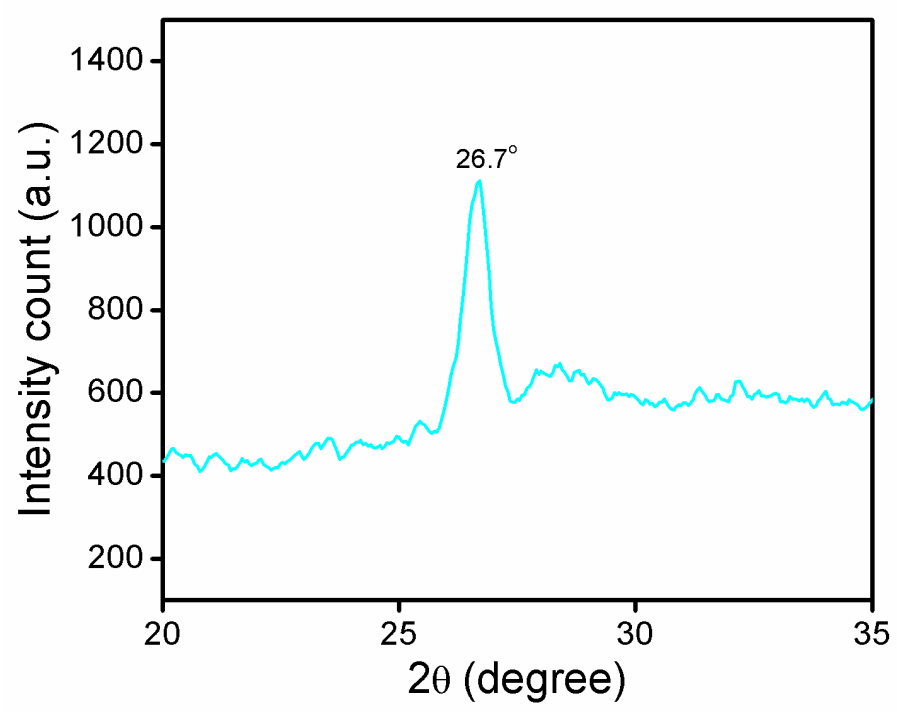

Figure S1. PXRD pattern of the hydrogel.

3.2 CD analysis of the hydrogel: The presence of positive signals at $\sim 293$ and $\sim 278 \mathrm{~nm}$, and negative signals at $\sim 284$ and $\sim 271 \mathrm{~nm}$ in the $\mathrm{CD}$ spectrum of the hydrogel confirms the formation of G-quadruplex like assembly of the G-quartets within the hydrogel (Figure S2). ${ }^{1,2}$

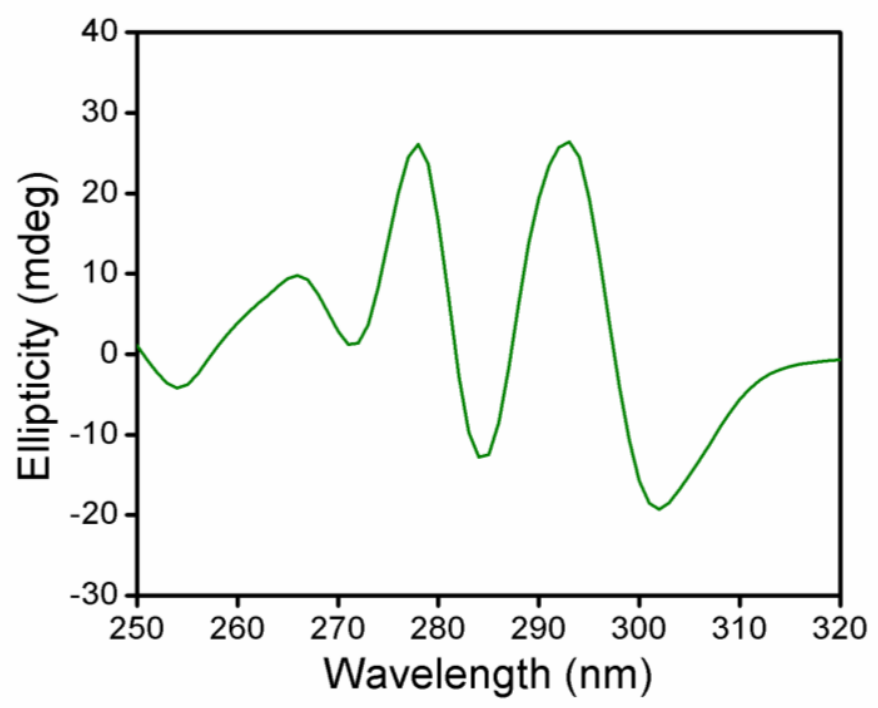

Figure S2. CD spectrum of the G4-PhB hydrogel. 
3.3 TEM and AFM analysis: For the TEM and AFM experiments, $1.5 \mathrm{mg}$ of the G4-PhB hydrogel was diluted with $400 \mu \mathrm{L}$ MilliQ water to obtain a transparent dispersion. Both these studies indicated the presence of an entangled network of long fiber like structures formed by stacking of G-quartet units (Figure S3).

a)

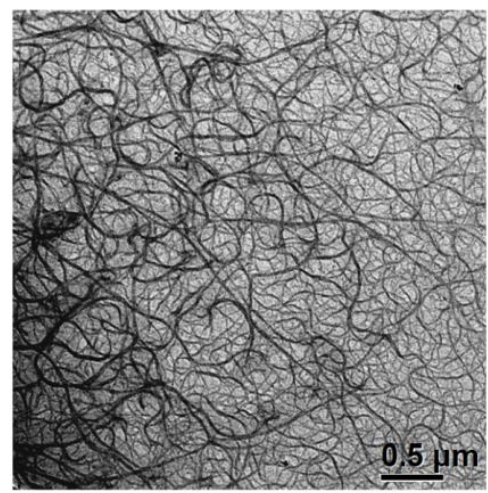

b)

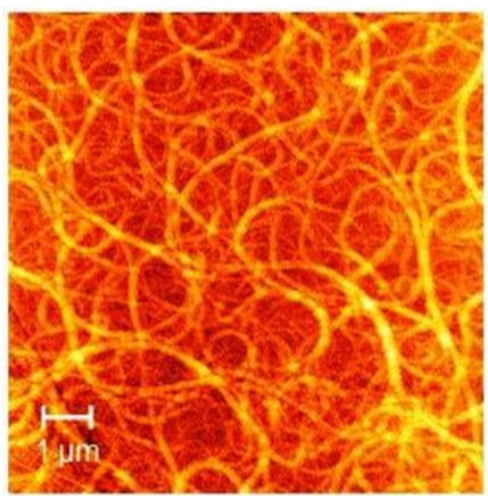

Figure S3. (a) TEM image of the G4-PhBhydrogel, (b) AFM image of the G4-PhBhydrogel.

3.4 NMR Spectroscopy (Solution Phase): ${ }^{1} \mathrm{H}$ NMR spectra of the G4-PhB hydrogel under different conditions were recorded using a Bruker $400 \mathrm{MHz}$ instrument. The NMR spectra were recorded using $\mathrm{D}_{2} \mathrm{O}$ as solvent.

3.5 Rheological measurements: Samples for rheological measurements were prepared by incubating $2 \mathrm{~mL}$ G4-PhB hydrogel with $400 \mu \mathrm{L}$ (10 mM solution) of compound 6 and 7 or their respective azide and alkyne fragments in DMSO. 


\subsection{DSC analysis of the hydrogel:}

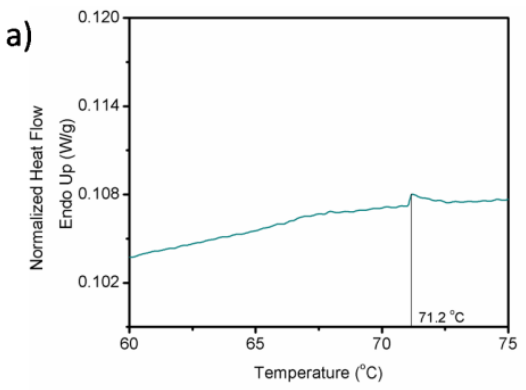

d)

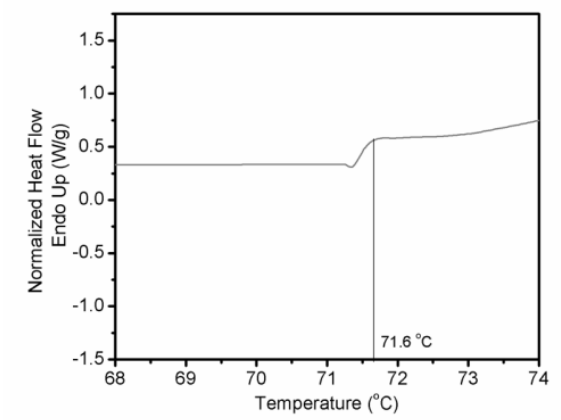

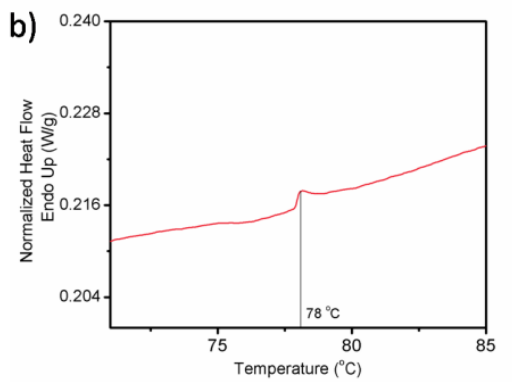

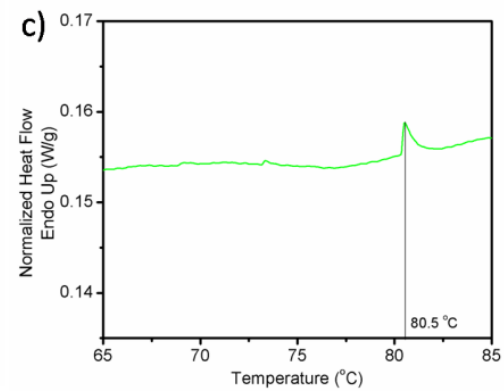

e)

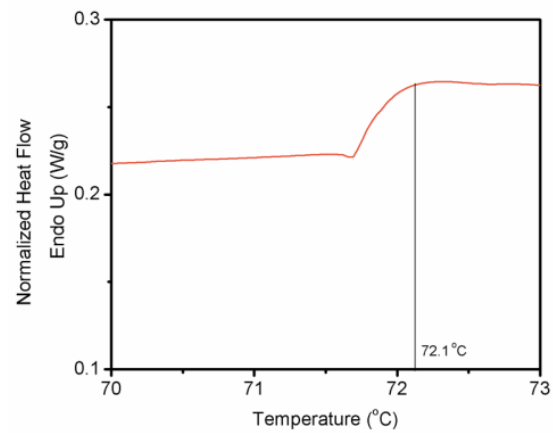

Figure S4. (a) DSC profile of the G4-PhB hydrogel, (b) DSC profile of the G4-PhB hydrogel incubated with alkyne $\mathbf{4 a}$ and azide $\mathbf{5 k}$, (c) DSC profile of the G4-PhB hydrogel incubated with compound 6, (d) DSC profile of the G4-PhB hydrogel incubated with alkyne $\mathbf{4 b}$ and azide $\mathbf{5 k}$, (e) DSC profile of the G4-PhB hydrogel incubated with compound 7.

4.0 Preparation and characterization of compounds: All the alkyne and azide building blocks and compound $\mathbf{6}$ were synthesized as per reported procedures., ${ }^{3,4}$

\subsection{Synthesis of triazole product 7:}

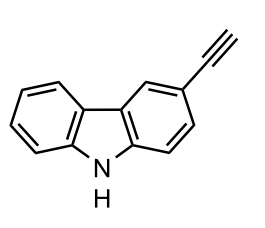

$4 b$<smiles>CN(C)CCCNC(=O)c1ccc([N+](=O)[O-])cc1</smiles>

$5 \mathbf{k}$

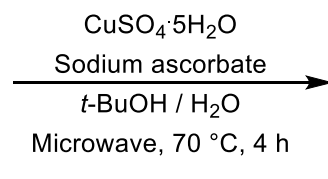

Microwave, $70^{\circ} \mathrm{C}, 4 \mathrm{~h}$

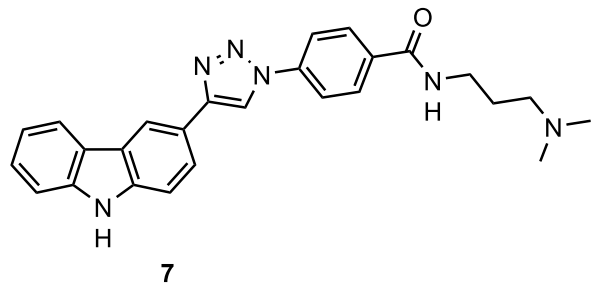

Scheme S1. Synthesis of 1,4-disubstituted triazole product 7 via $\mathrm{Cu}(\mathrm{I})$ catalyzed cycloaddition of alkyne $\mathbf{4 b}$ and azide $\mathbf{5 k}$.

A solution of carbazole alkyne $4 \mathbf{b}(31.7 \mathrm{mg}, 0.166 \mathrm{mmol})$ in a $1: 2$ mixture of $t-\mathrm{BuOH} / \mathrm{H}_{2} \mathrm{O}(3$ $\mathrm{mL}$ ) was taken in a $5 \mathrm{~mL}$ microwave vial with a stir bar. Copper (II) sulphate pentahydrate (4.1 
$\mathrm{mg}, 0.0166 \mathrm{mmol})$ and sodium ascorbate $(3.3 \mathrm{mg}, 0.0166 \mathrm{mmol})$ were then added to this solution and the resulting suspension was stirred for $10 \mathrm{~min}$. 1.2 equiv. of the azide $\mathbf{5 k}$ (49.4 $\mathrm{mg}, 0.2$ mmol) was then added to this mixture. The loaded microwave vial was then sealed with a cap and placed in the microwave reactor. Next, first the microwave reactor lid was closed, and then reaction temperature was set to $70{ }^{\circ} \mathrm{C}$ and reaction time set to $4 \mathrm{~h}$. Then, the reaction was allowed to run and the mixture heated for $4 \mathrm{~h}$ at $70{ }^{\circ} \mathrm{C}$ under microwave irradiation (Scheme S1). Once $4 \mathrm{~h}$ was over and the microwave irradiation stopped, the reaction mixture was allowed to cool (remain in the reactor) till the the reactor lid automatically opened. This reaction mixture was then concentrated under reduced pressure. This crude product obtained was then further purified by silica gel column chromatography [from $\mathrm{CH}_{2} \mathrm{Cl}_{2}(100 \%)$ to $\mathrm{CH}_{2} \mathrm{Cl}_{2} / \mathrm{MeOH}$ (10:1) to $\left.\mathrm{CH}_{2} \mathrm{Cl}_{2} / \mathrm{MeOH} / \mathrm{NH}_{4} \mathrm{OH}(10: 1: 0.5)\right]$ to give the corresponding triazole product 7 (46 mg, 63\%) as a viscous yellow liquid.

${ }^{1}$ H NMR (400 MHz, DMSO-d $\left.{ }_{6}\right): 11.47(\mathrm{~s}, 1 \mathrm{H}), 9.38(\mathrm{~s}, 1 \mathrm{H}), 8.70(\mathrm{~s}, 2 \mathrm{H}), 8.17$ (d, J = $7.3 \mathrm{~Hz}$, $1 \mathrm{H}), 8.10(\mathrm{~s}, 4 \mathrm{H}), 8.00(\mathrm{~d}, J=8.1 \mathrm{~Hz}, 1 \mathrm{H}), 7.61(\mathrm{~d}, J=8.1 \mathrm{~Hz}, 1 \mathrm{H}), 7.52(\mathrm{~d}, J=7.3 \mathrm{~Hz}, 1 \mathrm{H})$, 7.44-7.40 (m, 1H), 7.22-7.20 (m, 1H), $3.33(2 \mathrm{H}$, merged with water peak), $2.29(\mathrm{t}, J=6.7 \mathrm{~Hz}$, 2H), $2.15(\mathrm{~s}, 6 \mathrm{H})$ and $1.69(\mathrm{t}, J=6.1 \mathrm{~Hz}, 2 \mathrm{H}) \mathrm{ppm}$.

${ }^{13}$ C NMR (100 MHz, DMSO-d6):165.1, 148.8, 142.1, 140.2, 139.7, 138.4, 134.2, 131.1, 129.0, $125.9,123.4,122.7,122.3,120.7,120.2,119.3,118.2,117.2,111.4,56.4,45.5,37.5$ and $26.5 \mathrm{ppm}$.

HRMS ESI (m/z):[M+H] ${ }^{+}$Calcd for $\mathrm{C}_{26} \mathrm{H}_{27} \mathrm{~N}_{6} \mathrm{O} 439.2246$; Found 439.2243. 


\section{2 ${ }^{1} \mathrm{H}$ NMR and ${ }^{13} \mathrm{C}$ NMR spectra of compound 7:}

${ }^{1}$ H NMR (400 MHz, DMSO-d 6 ):

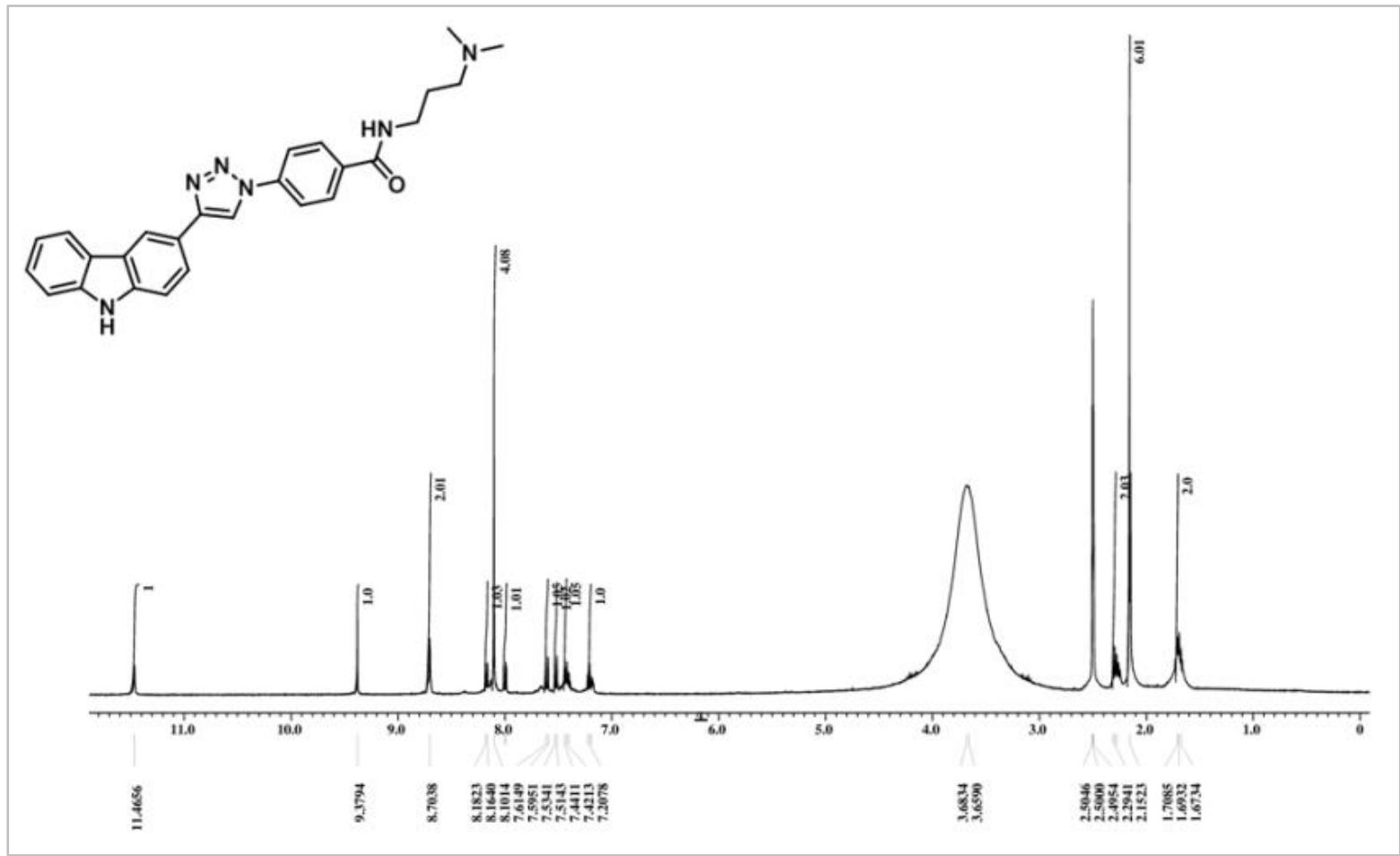

${ }^{13}$ C NMR (100 MHz, DMSO-d 6 ):

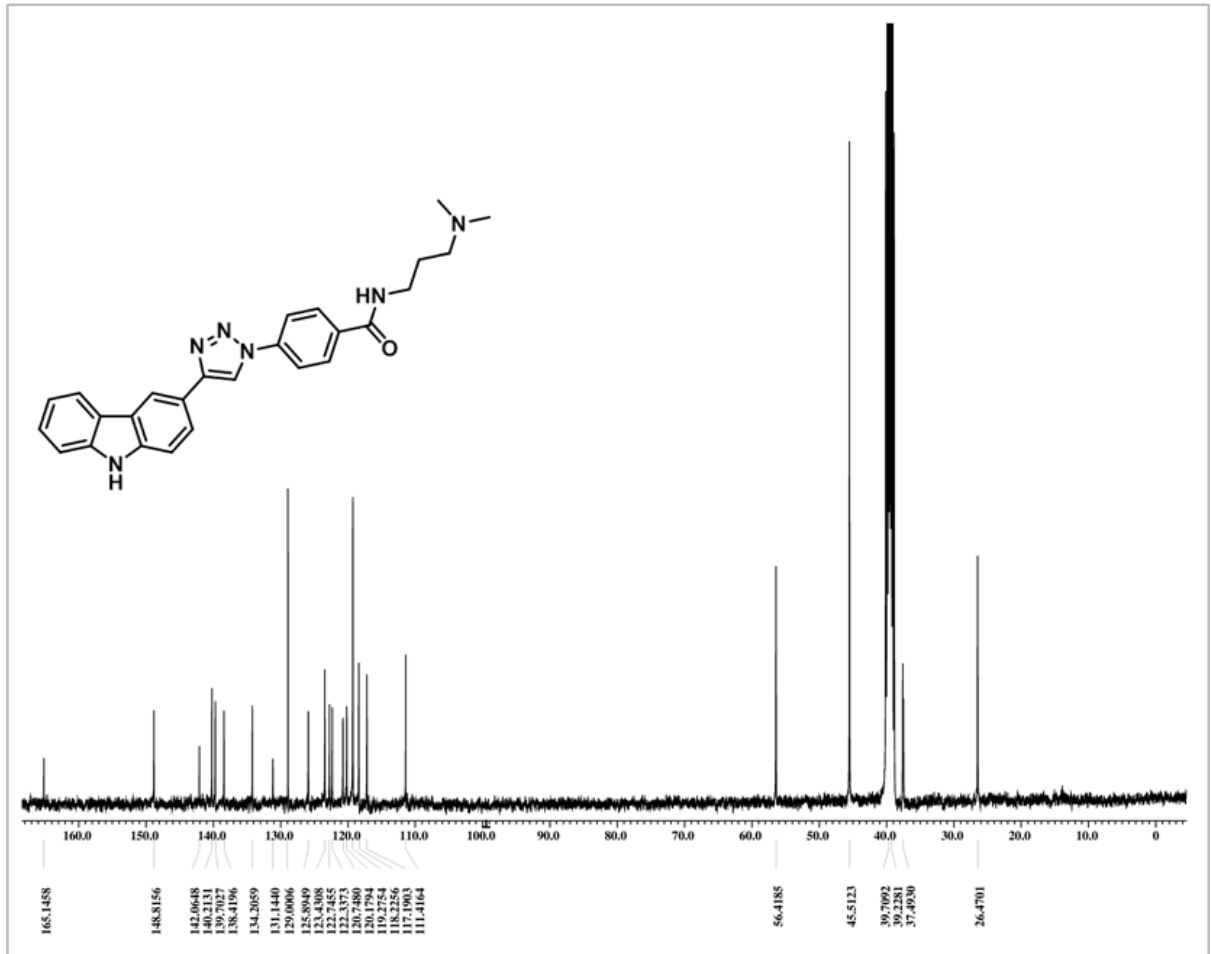




\subsection{HPLC chromatograms of compound 6 and 7:}

HPLC of compound $6(\mathrm{ODS} 2$, water/acetonitrile $=10 / 90$, flow rate $=0.5 \mathrm{~mL} / \mathrm{min}, 1=280 \mathrm{~nm})$ $\mathrm{tR}=5.152 \min$ (compound $\mathbf{6})$.

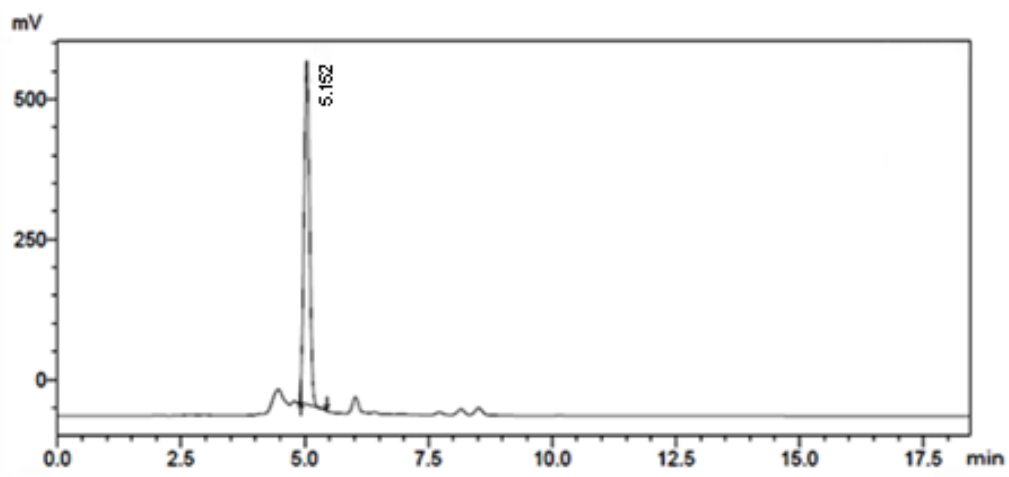

Figure S5. HPLC chromatogram for compound 6.

HPLC of compound $7(\mathrm{ODS} 2$, water/acetonitrile $=10 / 90$, flow rate $=0.5 \mathrm{~mL} / \mathrm{min}, 1=280 \mathrm{~nm})$ $\mathrm{tR}=6.410$ min (compound 7$).$

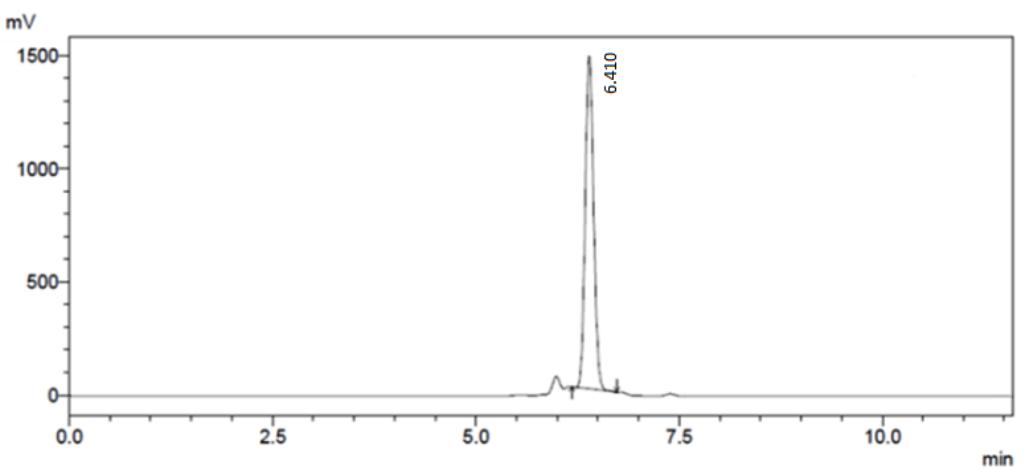

Figure S6. HPLC chromatogram for compound 7.

6.0 G4-PhB templated cycloaddition: $100 \mu \mathrm{L}$ thermoreversible G4-PhB gel was just melted to viscous sol state by very mild heating and then a mixture of alkyne $4 \mathbf{a}^{-c^{3,4}}(1 \mu \mathrm{L}$ of a $10 \mathrm{mM}$ solution in DMSO for each alkyne) and azide fragments $\mathbf{5 a - 1}-\mathbf{1}^{3,4}(4 \mu \mathrm{L}$ of a $10 \mathrm{mM}$ solution in DMSO of each azide) (in 1:4 ratio) was added into it. They were mixed well and the resulting homogeneous suspension was cooled to form a gel again. This gel system containing the azide 
and alkyne building blocks was incubated for 5 days. The formation of triazole compounds 6 and 7 was confirmed by ESI mass analysis of the resulting reaction mixture. The gel system was further destroyed by the addition of $1 \mu \mathrm{L}$ of $1 \mathrm{M} \mathrm{HCl}$ to give a turbid suspension $(\mathrm{pH} \sim 6.5)$. This turbid solution was then filtered using a syringe filter (pore size 0.22 micron) to remove as much guanosine possible. The filtrate obtained was further half diluted to carry out HPLC analysis. HPLC $($ ODS2, water/acetonitrile $=10 / 90$, flow rate $=0.5 \mathrm{~mL} / \mathrm{min}, 1=280 \mathrm{~nm}) \mathrm{tR}=4.1 \mathrm{~min}$ (guanosine-phenylboronate ester), $4.7 \mathrm{~min}$ (guanosine), $5.1 \mathrm{~min}(6), 6.4 \mathrm{~min}(7)$.

The relative yields of the compounds formed were calculated from the area of the peak representing the respective compounds in the HPLC chromatogram.

6.1 Control experiments: Several control experiments were carried out (Table S1) to confirm that the vital factor behind the product formation is the presence of stacked G-quartet assembly within the gel fibers.

Table S1.Optimization of reaction conditions.

\begin{tabular}{|c|c|}
\hline Experiments & Observations \\
\hline Aqueous solution of guanosine + alkynes + azides & No reaction (NR) \\
\hline $\begin{array}{l}\text { Aqueous solution of phenylboronic acid }+ \text { alkynes }+ \\
\text { azides }\end{array}$ & NR \\
\hline Aqueous solution of $\mathrm{KOH}+$ alkynes + azides & NR \\
\hline $\begin{array}{l}\text { Aqueous solution of guanosine }+ \text { phenylboronic } \\
\text { acid }+ \text { alkynes }+ \text { azides }\end{array}$ & NR \\
\hline $\begin{array}{l}\text { Aqueous solution of guanosine }+\mathrm{KOH}+\text { alkynes }+ \\
\text { azides }\end{array}$ & NR \\
\hline $\begin{array}{c}\text { Aqueous solution of phenylboronic acid }+\mathrm{KOH}+ \\
\text { alkynes }+ \text { azides }\end{array}$ & NR \\
\hline $\begin{array}{l}\text { Aqueous solution of guanosine }+ \text { phenylboronic } \\
\text { acid }+\mathrm{KOH}+\text { alkynes }+ \text { azides }\end{array}$ & Formation of products 6 and 7 \\
\hline
\end{tabular}

6.2 Determination of the rate of formation of 6: To estimate the rate of formation of the product (amount of product formed with time), different experimental set-ups of G4-PhB gel $(100 \mu \mathrm{L})$ containing equal amounts of building blocks $(2 \mu \mathrm{L}$ of a $10 \mathrm{mM}$ solution in DMSO of 
each alkyne 4a and azide 5k) were prepared. Each was disturbed using $1 \mu \mathrm{L} 1 \mathrm{M} \mathrm{HCl}$, at different incubation time interval. Relative amount of product obtained at different time intervals was calculated from the area of the peak representing compound $\mathbf{6}$ in the HPLC chromatogram of the reaction mixture at a particular time. The $\%$ relative yield was calculated considering the amount of product formed after 5 days to be $100 \%$. The plot of $\%$ relative yield with respect to time showed that saturation was reached at a time period of 3 days.

Table S2. \% Relative yield of 6 at different time intervals

\begin{tabular}{|c|c|}
\hline Time (h) & \% Relative Yield \\
\hline 0 & 0 \\
\hline 3 & 47.7 \\
\hline 6 & 51.3 \\
\hline 12 & 54.1 \\
\hline 24 & 58.9 \\
\hline 36 & 75.6 \\
\hline 48 & 88.4 \\
\hline 72 & 90.5 \\
\hline 96 & 98.9 \\
\hline 120 & 100 \\
\hline
\end{tabular}

\section{Calculation of initial rate of reaction:}

To calculate the rate of reaction ${ }^{5}$, different experimental set-ups of G4-PhB gel $(100 \mu \mathrm{L})$ containing equal amounts of building blocks $(2 \mu \mathrm{L}$ of a $10 \mathrm{mM}$ solution in DMSO of each alkyne 4a and azide 5k) were prepared. Each was disturbed using $1 \mu \mathrm{L} 1 \mathrm{M} \mathrm{HCl}$, at different incubation time interval. HPLC analysis of the reaction mixture obtained at each particular time was carried out.

The equation for [3+2] Huisgen Cycloaddition : Alkyne + Azide $\longrightarrow$ Triazole Product 
Therefore, as per the reaction, 1 mole of alkyne reacts with 1 mole azide to form 1 mole product.

Now, $2 \mu \mathrm{L}$ of $10 \mathrm{mM}$ solution of alkyne and $2 \mu \mathrm{L}$ of $10 \mathrm{mM}$ solution of azide in DMSO was added to $100 \mu \mathrm{L}$ of gel and each setup disturbed using $1 \mu \mathrm{L} \mathrm{HCl}$.

Therefore, final volume $=105 \mu \mathrm{L}$

Therefore, [alkyne] in the reaction mixture $=[$ azide $]$ in the reaction mixture $=0.19 \mathrm{mM}$

Therefore, theoretical yield of product (compound 6) $=0.19 \mathrm{mM}$

Relative amount of product obtained, was then calculated by comparing the area of the peak representing compound 6 in the HPLC chromatogram of the reaction mixture at a particular time with the peak area in HPLC chromatogram obtained when a $0.19 \mathrm{mM}$ of compound 6 in DMSO was injected.

Experimental yield of product (compound 6) after 5 days $=0.076 \mathrm{mM}$

[Percent yield $=(0.076 / 0.19) \times 100=40 \%]$

[Compound 6] at different time intervals have been tabulated in Table S3 below:

Table S3. Concentration of Compound 6 at different time intervals

\begin{tabular}{|c|c|}
\hline Time (h) & [Compound 6] in mM \\
\hline 0 & 0 \\
\hline 3 & 0.036 \\
\hline 6 & 0.038 \\
\hline 12 & 0.041 \\
\hline 24 & 0.044 \\
\hline 36 & 0.057 \\
\hline 48 & 0.067 \\
\hline
\end{tabular}




\begin{tabular}{|c|c|}
\hline 72 & 0.068 \\
\hline 96 & 0.075 \\
\hline 120 & 0.076 \\
\hline
\end{tabular}

A graph of Product concentration Vs Time was plotted using the above data.

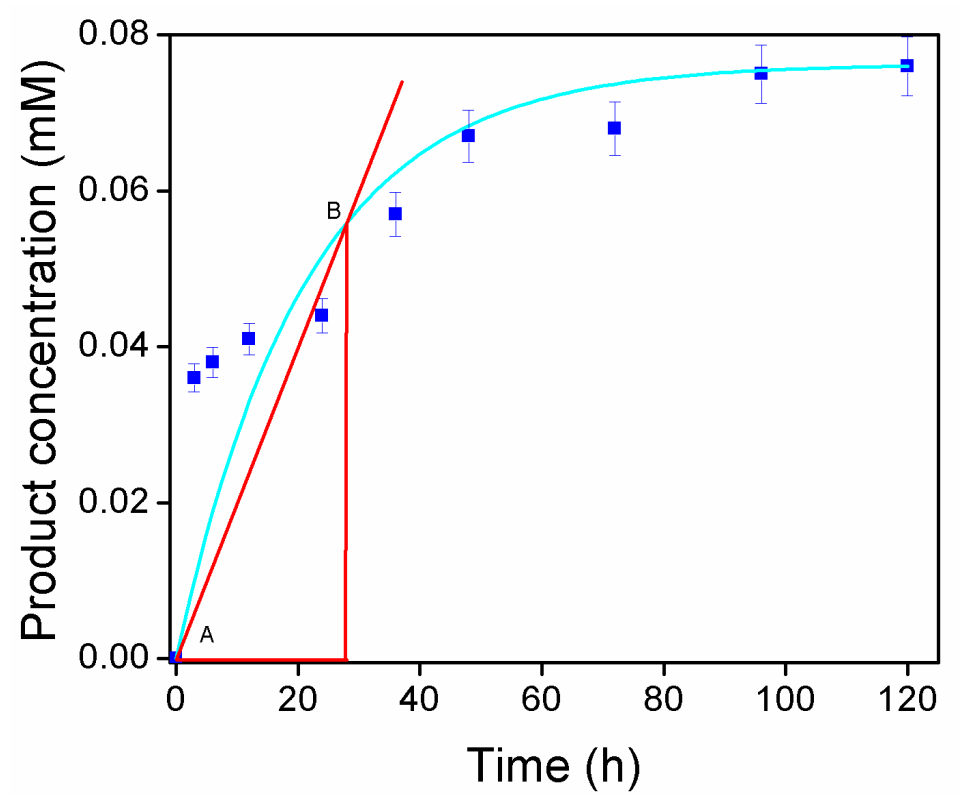

Figure S7. The graphical representation of the rate of $\mathrm{G} 4-\mathrm{PhB}$ gel templated formation of product 6

From the graph;

[Product] at $\mathrm{A}=0 \mathrm{mM}$ and [Product] at $\mathrm{B}=0.055 \mathrm{mM}$

Time at $\mathrm{A}=0 \mathrm{~h}$ and time at $\mathrm{B}=27.69 \mathrm{~min}$

Therefore, from the graph; initial rate of the reaction $=$ change in concentration of product $/$ time interval $=[$ concentration of product at $\mathrm{B}-$ concentration of product at $\mathrm{A}] /$ [Time at point $\mathrm{B}$ Time at point $\mathrm{A}]=(0.055-0) /(27.69-0)=0.055 / 27.69=1.99 \times 10^{-3} \mathrm{mM} / \mathrm{h}$

Therefore, initial rate of reaction $=1.99 \times 10^{-3} \mathrm{mM} / \mathrm{h}$ 


\subsection{Determination of the regiochemistry of the compound 6:}

The regiochemistry of the triazole compound $\mathbf{6}$, generated by G4-PhB templated cycloaddition, was determined by comparing the HPLC traces of the product obtained from the gel templated cycloaddition with the products obtained from thermal and $\mathrm{Cu}(\mathrm{I})$ catalyzed reactions between alkyne $\mathbf{4 a}$ and azide $\mathbf{5 k}$.

(a)

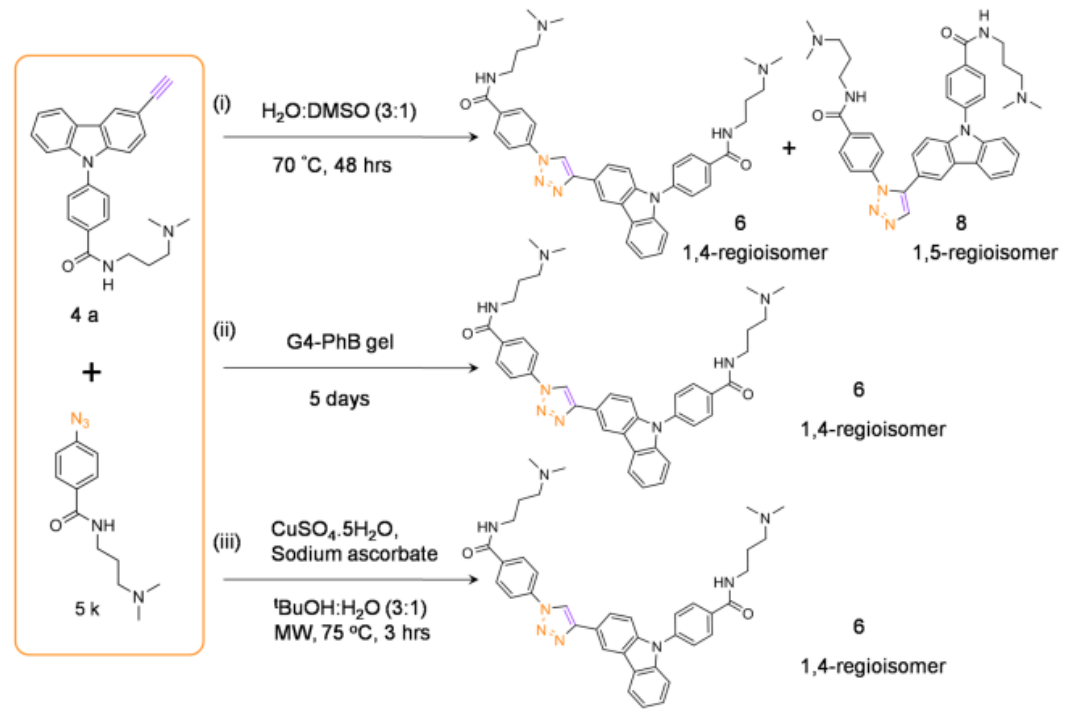

(b)
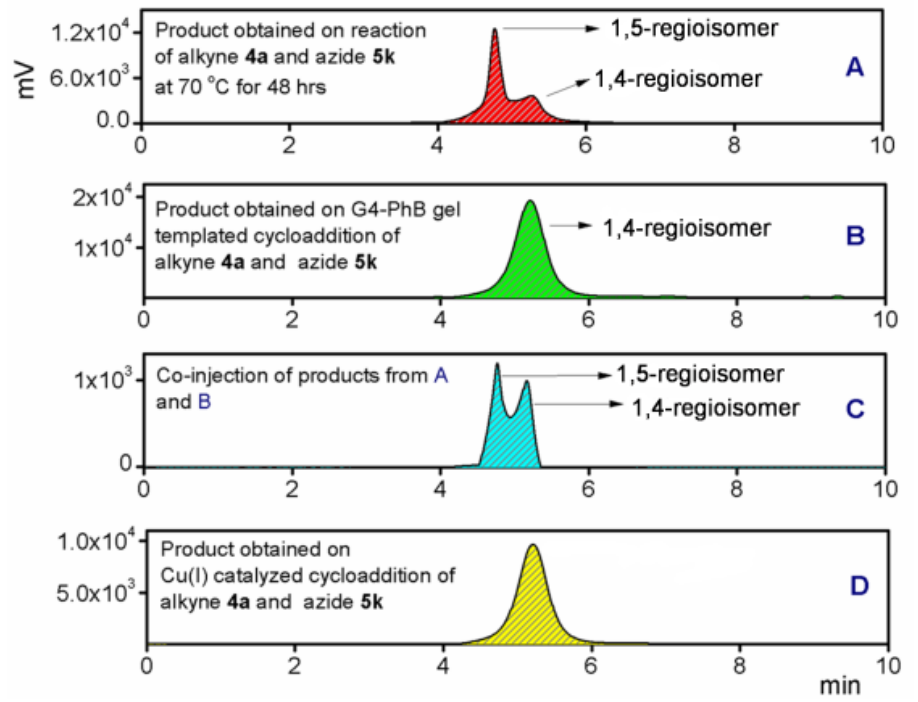

Figure S8. (a) Cycloaddition of alkyne $4 \mathrm{a}$ and azide 5k under different conditions: (i) thermal, (ii) $\mathrm{G} 4-\mathrm{PhB}$ gel templated reaction, (iii) $\mathrm{Cu}$ (I) catalyzed reaction.(b) Determination of the regiochemistry of the compound $\mathbf{6}$ formed by gel templated cycloaddition: A. HPLC chromatogram representing reaction (i), B. HPLC chromatogram representing reaction (ii), C. HPLC chromatogram representing co-injection of A and B, D. HPLC chromatogram representing reaction (iii). 
7.0 G-BrG templated cycloaddition: $100 \mu \mathrm{L}$ thermoreversible G-BrG gel was allowed to just melt to the viscous sol state by very mild heating and then a mixture of alkyne $4 \mathbf{a}-\mathrm{c}^{3,4}$ ( $1 \mu \mathrm{L}$ of a

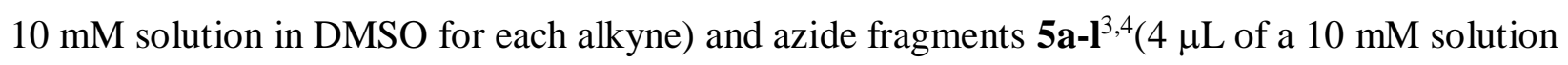
in DMSO of each azide) (in 1:4 ratio) was added into it. They were mixed well to give a homogeneous suspension, which was cooled to form a gel again. This gel system containing the azide and alkyne building blocks was incubated for 5 days. The formation of triazole compounds 6 and 7 was confirmed by ESI mass analysis of the resulting reaction mixture. This gel system was further destroyed by addition of $1 \mu \mathrm{L}$ of $0.5 \mathrm{M} \mathrm{HCl}$ to give a turbid suspension ( $\mathrm{pH} \sim 3.9$ ). This turbid solution was then filtered using a syringe filter (pore size 0.22 micron) to remove as much guanosine and 8-bromoguanosine possible. The filtrate obtained was further half diluted to carry out HPLC analysis.

HPLC $($ ODS2, water/acetonitrile $=10 / 90$, flow rate $=0.5 \mathrm{~mL} / \mathrm{min}, 1=280 \mathrm{~nm}) \mathrm{tR}=4.2 \mathrm{~min}(8-$ bromoguanosine), $4.7 \min$ (Guanosine), $5.2 \min (\mathbf{6}), 6.4 \min (7)$.

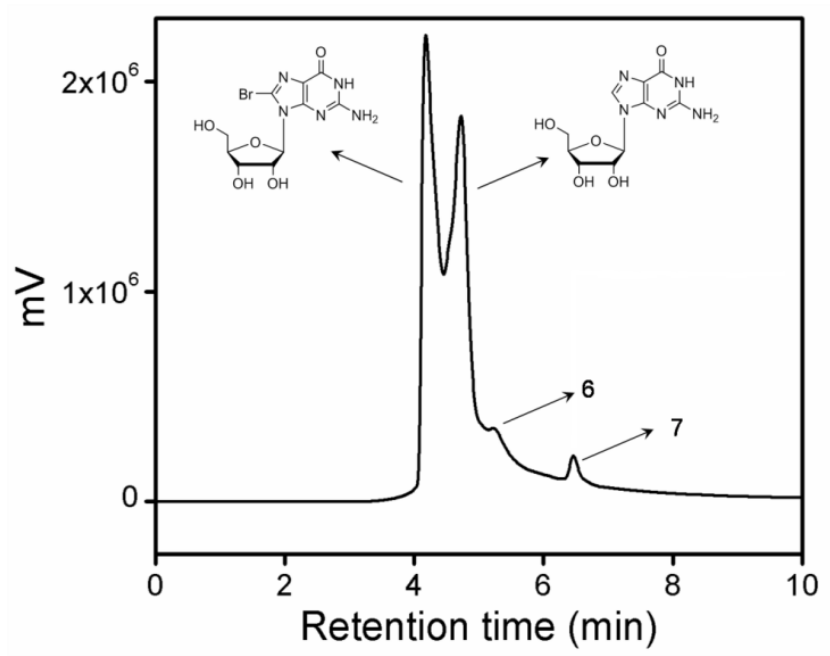

Figure S9. HPLC chromatogram of the filtrate obtained on destroying the G-BrG gel.

The relative yields of the compounds formed were calculated from the area of the peak representing the respective compounds in the HPLC chromatogram. 


\subsection{References:}

1)Bhattacharyya, T.; Kumar, Y. P.; Dash, J. Supramolecular hydrogel inspired from DNA structures mimics peroxidase activity. ACS Biomater. Sci. Eng. 2017, 3, 2358-2365.

2) Burge, S.; Parkinson, G. N.; Hazel, P.; Todd, A. K.; Neidle, S.Quadruplex DNA: sequence, topology and structure. Nucleic Acids Res. 2006, 34, 5402-5415.

3) Panda, D.; Saha, P.; Das, T.; Dash, J. Target guided synthesis using DNA nano-templates for selectively assembling a G-quadruplex binding c-MYC inhibitor. Nat. Commun. 2017, 8, 1610316114.

4) Saha, P.; Panda, D.; Müller, D.; Maity, A.; Schwalbe, H.; Dash, J. In situ formation of transcriptional modulators using non-canonical DNA $i$-motifs. Chem. Sci. 2020, 11, 2058-2067.

5) (a) Tang, Q.; Leyh, T. S. Precise, facile initial rate measurements. J. Chem. Phys. B 2010, 114, 16131-16136. (b) El-Zaatari, B. M.; Shete, A. U.; Adzima, B. J.; Kloxin, C. J. Towards understanding the kinetic behaviour and limitations in photo-induced copper (I) catalyzed azidealkyne cycloaddition (CuAAC) reactions.Phys. Chem. Chem. Phys. 2016 , 18, 25504-25511. 